MRS Advances (C) 2019 Materials Research Society. This is an Open Access article, distributed under the terms of the Creative Commons Attribution licence (http:// creativecommons.org/licenses/by/4.0/), which permits unrestricted re-use, distribution, and reproduction in any medium, provided the original work is properly cited.

DOI: $10.1557 /$ adv.2019.65

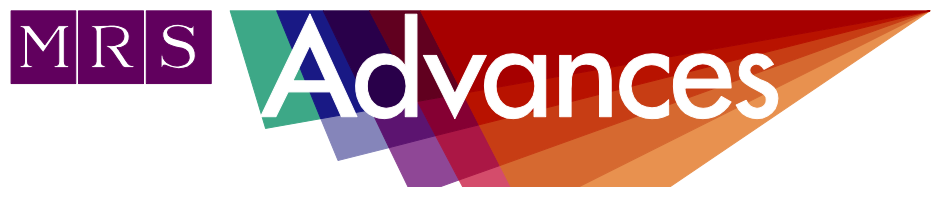

\title{
Synthesis and Characterization of $c$-Axis Oriented Zinc Oxide Thin Film and Its Use for the Subsequent Hydrothermal Growth of Zinc Oxide Nanorods
}

S.F.U. Farhad, ${ }^{1 *}$ N.I. Tanvir, ${ }^{1}$ M.S. Bashar ${ }^{2}$, and M. Sultana ${ }^{2}$

${ }^{1}$ Solar Energy Conversion and Storage Research Section, Industrial Physics Division, BCSIR Labs, Dhaka 1205

${ }^{2}$ Institute of Fuel Research and Development (IFRD), Dhaka 1205, Bangladesh Council of Scientific and Industrial Research (BCSIR), Bangladesh

*E-mail: sf1878@my.bristol.ac.uk / Phone: (0088) 01881755767

\section{ABSTRACT}

Oriented $\mathrm{ZnO}$ seed layers were deposited by three different techniques, namely, simple drop casting (DC), sol-gel derived dip coating (DPC) and spin coating of ball-milled $\mathrm{ZnO}$ powder solution(BMD) for the subsequent growth of vertically aligned $\mathrm{ZnO}$ nanorods along the substrate normal. $X$-ray diffraction $(X R D)$ analyses revealed that $\mathrm{ZnO}(D C)$ seed layer exhibit the highest preferential c-axis texturing among the $\mathrm{ZnO}$ seed layers synthesized by different techniques. The Scanning Electron Microscopy (SEM) analysis evident that the morphology of $\mathrm{ZnO}$ seed layer surface is compact and coherently carpets the underlying substrate. $\mathrm{ZnO}$ nanorods(NRs) were then grown by hydrothermal method atop the $\mathrm{ZnO}$ seeded and nonseeded substrates grown by different techniques to elucidate the best $\mathrm{ZnO}$ seed layer promoting well-aligned $\mathrm{ZnO}$ Nanorods. The presence of c-axis oriented $\mathrm{ZnO}(D C)$ seeding layers was found to significantly affect the surface morphology and crystallographic orientation of the resultant $\mathrm{ZnO} N$ Rs films. The optical band gap of $\mathrm{ZnO}(\mathrm{DC})$ seed and $\mathrm{ZnO}$ NRs were estimated to be $3.30 \mathrm{eV}$ and in the range of $3.18-3.25 \mathrm{eV}$ respectively by using $U V$-VIS-NIR diffuse reflection spectroscopy. The room temperature photoluminescence analyses revealed that nanostructured $\mathrm{ZnO}$ films exhibit a sharp near-band-edge luminescence peak at $\sim 380 \mathrm{~nm}$ consistent with the estimated optical band gap and the $\mathrm{ZnO}$ nanorod arrays are notably free from defect-related green-yellow emission peaks. 


\section{INTRODUCTION}

Zinc Oxide $(\mathrm{ZnO})$ is one of the most promising II - VI group semiconductors generally crystallizes in the thermodynamically most stable hexagonal wurtzite structure. $\mathrm{ZnO}$ naturally exhibits n-type conductivity due to the formation of oxygen vacancies in the crystal lattice and has a wide direct band gap of $3.37 \mathrm{eV}$ at room temperature [1-3]. Furthermore, $\mathrm{ZnO}$ is an environmentally benign, chemically stable and mechanically robust material and can be grown by number of deposition techniques [2, 4]. These intriguing properties together with wide range of multi-functionalities make $\mathrm{ZnO}$ material a potential candidate for a wide variety of applications [1,2]. Recently, nano scale single crystalline $\mathrm{ZnO}$ materials such as nanorods (NRs), nanowires (NWs), nanotubes (NTs) etc. have been gained much attention because of their unique physical properties compared to their bulk counterpart. Synthesis of vertically aligned ZnO NRs along the $c$-axis direction is desirable for various device design and applications (for example $\mathrm{ZnO} / \mathrm{Cu}_{2} \mathrm{O}$ based radial-junction $\left.[3,5]\right)$ in order to attain efficient charge carrier transport and collection [2]. Pre-depositing a $c$-axis textured $\mathrm{ZnO}$ thin seeding layer offers vital nucleation centers for growing vertically aligned $\mathrm{ZnO} \mathrm{NR}$ assemblies along the substrate normal. In this study, three different techniques, namely, simple drop casting (DC), sol-gel-derived dip coating (DPC) and spin coating of ball-milled $\mathrm{ZnO}$ powder solution (BMD) have been employed for producing (0002) oriented $\mathrm{ZnO}$ thin seeding layers. ZnO NRs were then grown by hydrothermal method atop these $\mathrm{ZnO}$ thin seed layers to elucidate the most effective $\mathrm{ZnO}$ seeding techniques for the growth of vertically-aligned $\mathrm{ZnO}$ NRs. The structural, morphological, optical and photoluminescence properties of $\mathrm{ZnO} \mathrm{NRs}$ grown on $\mathrm{ZnO}$ seed thin films by three different techniques were investigated and discussed.

\section{EXPERIMENTAL}

Prior to actual seed layer deposition, all substrates were cleaned by sequential ultra-sonication in acetone, isopropanol, and finally in deionized (DI) water (Resistivity $\sim 18 \mathrm{M} \Omega . \mathrm{cm}$ ) each for $15 \mathrm{~min}$ followed by a hot air blown dry. $c$-Axis oriented $\mathrm{ZnO}$ thin seed layers grown by simple drop casting technique ( $\mathrm{ZnO}(\mathrm{DC}))$ were reported previously [2]. Dip-coated $\mathrm{ZnO}$ thin seed layers ( $\mathrm{ZnO}(\mathrm{DPC})$ ) were grown on soda lime glass (SLG) from 0.3 M solution of Zinc acetate di-hydrate (ZAD) dissolved in ethanol. On the other hand, bulk $\mathrm{ZnO}$ powder (purity 99.99\%) were ball-milled for 36 hours and then required amount of ball-milled powder (crystallite size $(L C) \sim 22 \mathrm{~nm}$ ) were dispersed into absolute ethanol to make $0.020 \mathrm{M}$ colloidal solution of $\mathrm{ZnO}$. This solution was then spun-coated ( $2500 \mathrm{rpm}$ for $1 \mathrm{~min})$ on FTO substrate for obtaining ZnO thin seed layers ( $\mathrm{ZnO}(\mathrm{BMD}))$. All $\mathrm{ZnO}$ seed layers deposited by three techniques were annealed at 250 ${ }^{0} \mathrm{C}$ in the air for 1 hour. $\mathrm{ZnO}$ NRs were then deposited atop the bare as well as the $\mathrm{ZnO}$ seeded SLG and FTO substrates by hydrothermal method described elsewhere in detail [2]. The hydrothermally grown thin films were given to the same post-heat treatment as that of seeding layer (heated at $250{ }^{\circ} \mathrm{C}$ in the air for 1 hour) for removing any organic deposits from the bath solution.

The crystalline structure, surface morphology, optical and luminescent properties of the synthesized products were characterized by XRD (GBC scientific; $\mathrm{Cu}_{-} \mathrm{K}_{\alpha 1}: \lambda=1.54062 \AA$ r radiation source), SEM (Hitachi S3400N), UV-VIS-NIR spectrometer coupled with an integrating sphere (Shimadzu 2600) and photoluminescence (PL) spectrometer (PHOTON SYSTEM; excitation source: HeAg 30 Deep UV laser, $\lambda_{\text {ext }} \approx 224 \mathrm{~nm}$; laser power $<1 \mathrm{~mW}$ ) respectively. 


\section{RESULTS AND DISCUSSION}

Figure 1 shows the normalized $\mathrm{XRD}$ patterns of $\mathrm{ZnO}(\mathrm{DC}), \mathrm{ZnO}(\mathrm{DPC})$ seed layers on SLG substrates and ZnO NRs on seeded SLG and FTO substrates as mentioned in the legend of the corresponding curve. The diffractogram of blank FTO substrate (gray curve) and pure $\mathrm{ZnO}$ powder (red curve) are also included in figure 1 for reference and comparison purposes. Pure $\mathrm{ZnO}$ powder exhibit

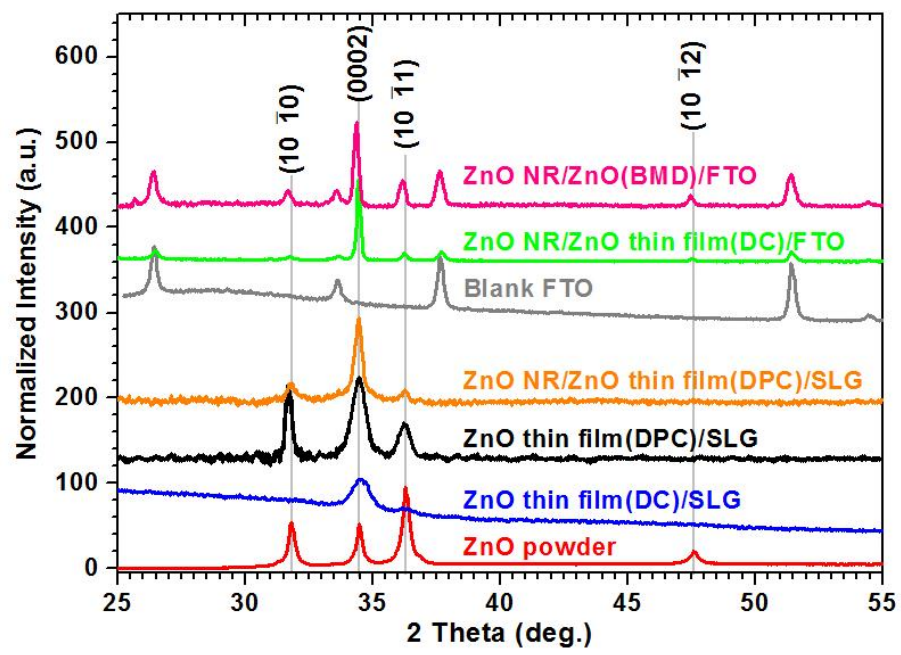

Figure 1. Normalized XRD patterns (vertically offset for clarity) of $\mathrm{ZnO}$ thin films and $\mathrm{ZnO}$ NRs deposited on seeded SLG and FTO substrates. Thin seed layers were prepared by drop casting(DP), dip-coating(DPC) and ball-milled derived(BMD) $\mathrm{ZnO}$ powder for spin coating of $\mathrm{ZnO}$ colloidal solution. The XRD pattern of bulk $\mathrm{ZnO}$ powder and blank FTO substrate are also included for comparison purposes.

well-defined Bragg peaks at $2 \theta \approx 31.8^{0}, 34.4^{0}, 36.2^{0}$, and $47.6^{0}$ which can be ascribed

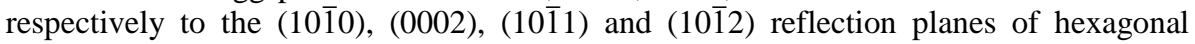
wurtzite structure. As can be seen, the diffractogram of $\mathrm{ZnO}(\mathrm{DC})$ seed layer exhibits a strong (0002) and a week (10111) reflection peak. In contrast, $\mathrm{ZnO}(\mathrm{DPC})$ seed layer exhibits Bragg peaks of (10 $\overline{1} 0),(0002),(10 \overline{1} 1)$ planes without any preferred orientation. Note that the relative intensity of (0002) Bragg peak in the $\mathrm{ZnO}(\mathrm{DC})$ sample suggesting that $\mathrm{ZnO}$ seed layers were grown with a predominant $c$-axis texturing $[6,7]$. The amount of $c$-axis texturing of all deposited samples was estimated by using the relation [2]: $T C(0002)=N\left[\left(I_{s}(0002) / I_{p}(0002)\right) /\left(\Sigma_{\mathrm{N}} I_{s}(h k i l) / I_{p}(h k i l)\right)\right]$; where, $h, k, l$, and $i=-(h+k)$ are the Miller indices for hcp crystal structure, $I_{s}(h k i l)$ and $I_{p}(h k i l)$ are the relative peak intensity of the deposited sample and $\mathrm{ZnO}$ powder (reference sample with random orientation) respectively, and $N$ is the number of Bragg reflections included in the analysis and the results are given in the table I. XRD patterns of ZnO NRs samples, regardless of substrate and seeding layer, are dominated by the (0002) basal plane reflections of wurtzite $\mathrm{ZnO}$ phase suggesting that $\mathrm{ZnO}$ NRs produced by hydrothermal method were grown along the $c$-axis [6-8], presumably parallel to the substrate normal [2]. The mean crystallite domain size $(L C)$ were estimated to be $L C \sim 9 \mathrm{~nm}$ for $\mathrm{ZnO}(\mathrm{DC}) / \mathrm{SLG}, \quad L C \sim 13 \mathrm{~nm}$ for $\mathrm{ZnO}(\mathrm{DPC}) / \mathrm{SLG}, \quad L C \sim 24 \mathrm{~nm}$ for $\mathrm{ZnO}$ $\mathrm{NR} / \mathrm{ZnO}(\mathrm{DPC}) / \mathrm{SLG}, L C \sim 45 \mathrm{~nm}$ for $\mathrm{ZnO} \mathrm{NR} / \mathrm{ZnO}(\mathrm{DC}) / \mathrm{FTO}$, and $L C \sim 43 \mathrm{~nm}$ for $\mathrm{ZnO}$ 
$\mathrm{NR} / \mathrm{ZnO}$ (BMD)/FTO by applying the Scherrer formula [2] to (0002) Bragg peak. Other important structural properties of $\mathrm{ZnO}$ nanostructured films were extracted from XRD analyses using similar approach employed in the reference [2] and summarized in table I for comparison purposes.

Table I. Structural properties obtained from X-ray diffractogram analysis.

\begin{tabular}{|c|c|c|c|c|c|}
\hline $\begin{array}{l}\text { Structural } \\
\text { Parameters }\end{array}$ & $\begin{array}{l}\mathrm{ZnO(DC)} \\
\text { seed/SLG }\end{array}$ & $\begin{array}{l}\mathrm{ZnO}(\mathrm{DPC}) \\
\text { seed } / \mathrm{SLG}\end{array}$ & $\begin{array}{l}\text { ZnO NRs } \\
\text { On ZnO } \\
\text { (DPC)/SLG }\end{array}$ & $\begin{array}{l}\text { ZnO NRs } \\
\text { on ZnO } \\
\text { (DC)/FTO }\end{array}$ & $\begin{array}{l}\text { ZnO NRs } \\
\text { on ZnO } \\
\text { (BMD)/FTO }\end{array}$ \\
\hline $\begin{array}{l}2 \theta(0002) \\
(\text { deg. })\end{array}$ & 34.44 & 34.45 & 34.46 & 34.46 & 34.36 \\
\hline$d(0002)(\mathrm{nm})$ & 0.26024 & 0.26017 & 0.26009 & 0.26009 & 0.26083 \\
\hline$a(\mathrm{~nm})$ & 0.31873 & 0.31864 & 0.31855 & 0.31855 & 0.31945 \\
\hline$c(\mathbf{n m})$ & 0.52048 & 0.52034 & 0.52019 & 0.52019 & 0.52166 \\
\hline FWHM (deg.) & 0.927 & 0.640 & 0.347 & 0.184 & 0.192 \\
\hline $\begin{array}{l}\text { Mean crystallite } \\
\text { domain size (nm) }\end{array}$ & 8.87 & 12.85 & 23.70 & 44.70 & 42.83 \\
\hline TC(0002) & 3.64 & 1.93 & 3.10 & 3.46 & 2.41 \\
\hline $\operatorname{Strain}\left(\varepsilon_{\mathrm{zz}}\right) \times 10^{-3}$ & 0.282 & 0 & -0.281 & -0.281 & 0.254 \\
\hline Stress(GPa) & -0.12 & 0 & 0.13 & 0.13 & -1.14 \\
\hline
\end{tabular}

As can be seen from table I, the $c$-axis texturing (TC(0002)) for $\mathrm{ZnO}(\mathrm{DC}) / \mathrm{SLG}$ is $\sim 3.64$ which is the highest among the samples studied and $\sim 2$ times higher compared to that of the $\mathrm{ZnO}(\mathrm{DPC}) / \mathrm{SLG}$ seed layer. For NRs grown on seeded substrates: $T C \sim 3.10$ for $\mathrm{ZnO} \mathrm{NR} / \mathrm{ZnO}(\mathrm{DPC}) / \mathrm{SLG}, T C \sim 3.46$ for $\mathrm{ZnO} \mathrm{NR} / \mathrm{ZnO}(\mathrm{DC}) / \mathrm{FTO}$, and $T C \sim 2.41$ for $\mathrm{ZnO} \mathrm{NR} / \mathrm{ZnO}(\mathrm{BMD}) / \mathrm{FTO}$. Notice the highly textured $\mathrm{ZnO}(\mathrm{DC})$ seed layer induced the highest $T C$ values for $\mathrm{ZnO} \mathrm{NRs}$. These observations suggest that $c$-axis textured $\mathrm{ZnO}(\mathrm{DC})$ seed layer indeed facilitates the formation of $c$-axis oriented $\mathrm{ZnO} \mathrm{NRs}$ along the substrate normal [2, 6-8]. Considering only the similar sample structure, the estimated biaxial stress in $\mathrm{ZnO} \mathrm{NR} / \mathrm{ZnO}(\mathrm{BMD}: 0.02 \mathrm{M} \mathrm{ZAD}) / \mathrm{FTO}$ and $\mathrm{ZnO}$ $\mathrm{NR} / \mathrm{ZnO}(\mathrm{DC}: 0.02 \mathrm{M} \mathrm{ZAD}) / \mathrm{FTO}$ are found compressive and tensile respectively. Mechnache et. al. [9] reported similar observations for their $\mathrm{ZnO} \mathrm{NR}$ film grown on glass, ITO/glass and AZO/glass substrates by spray pyrolysis at $\mathrm{T}_{\text {sub }}=350{ }^{\circ} \mathrm{C}$ and argued that the observed the change from compressive stress for $\mathrm{ZnO} \mathrm{NR/glass} \mathrm{to} \mathrm{tensile} \mathrm{stress}$ for $\mathrm{ZnO} \mathrm{NR} / \mathrm{ITO} /$ glass and $\mathrm{ZnO} \mathrm{NR} / \mathrm{AZO} /$ glass are due to the improvement of $c$-axis texturing. 

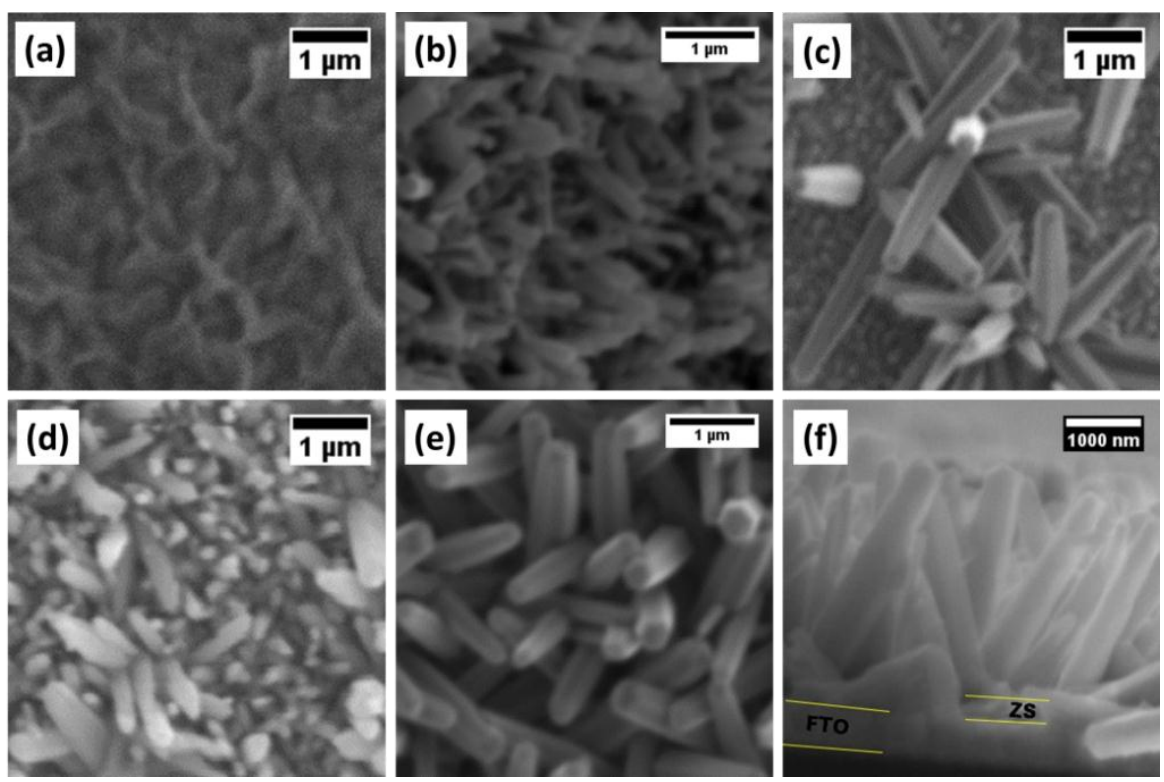

Figure 2. SEM micrographs of $\mathrm{ZnO}(\mathrm{DPC}) / \mathrm{SLG}$ (a), $\mathrm{ZnO} \mathrm{NR} / \mathrm{ZnO}(\mathrm{DPC}) / \mathrm{SLG}$ (b), $\mathrm{ZnO} \mathrm{NR} / \mathrm{FTO}$ (c); $\mathrm{ZnO}$ $\mathrm{NR} / \mathrm{ZnO}$ (BMD)/FTO (d), ZnO NR/ZS(DC)/FTO (e) and ZnO NR/ZS(DP)/FTO (f). (a) - (e) are plane view images and (f) is the cross-sectional view image.

Figure 2(a - e) compares the surface morphology $\mathrm{ZnO}$ NRs grown atop the seeded and non-seeded layers. The morphology of $\mathrm{ZnO}$ seed layer surface is seen to be compact and coherently carpets the underlying substrate (cf. figure 2(a), 2(c), and 2(f)) throughout the area investigated. As can be seen, $\mathrm{ZnO}$ NRs grown on $\mathrm{ZnO}$ (BMD) seed(figure 2(d)) are irregular-shaped and randomly oriented. ZnO NRs grown on $\mathrm{ZnO}(\mathrm{DPC})$ seed(figure 2(b)) are seen to be thin nanorods with no clearly defined hexagonal facets and they are poorly oriented. In contrast, ZnO NRs grown on blank FTO (figure 2(c)) and $\mathrm{ZnO}(\mathrm{DC})$ seeded FTO (figure 2(e)) exhibit well-defined hexagonal facets. Notice that FTO substrate seeded with $\mathrm{ZnO}$ (DC) produced the best aligned $\mathrm{ZnO}$ NRs among the samples investigated and they are basically vertically-oriented nanorods arrays as evident from the cross-sectional image of the same sample (figure 2(e)). In figure 2(e), $\mathrm{ZnO}(\mathrm{DC})$ seed layer (labeled by $\mathrm{ZS}$, thickness $232 \pm 34 \mathrm{~nm}$ ), FTO substrate (thickness $\sim 608 \pm 22 \mathrm{~nm}$ ), and vertically grown ZnO NRs ( Length $~ 3.2 \pm 0.1$ $\mu \mathrm{m}$ ) are evidently seen in the cross-sectional view of $\mathrm{ZnO} \mathrm{NR} / \mathrm{ZnO}(\mathrm{DC}) / \mathrm{FTO}$ film. Clearly, $c$-axis oriented $\mathrm{ZnO}(\mathrm{DC})$ seed layer produced highly $c$-axis textured $\mathrm{ZnO} \mathrm{NRs}$ evident from both XRD and SEM analyses (see figure 1 and figure 2). These observations also demonstrate the beneficial effect of pre-depositing of an oriented $\mathrm{ZnO}$ seed layer for the subsequent hydrothermal growth of vertically-aligned ZnO NRs along the $c$-axis. 


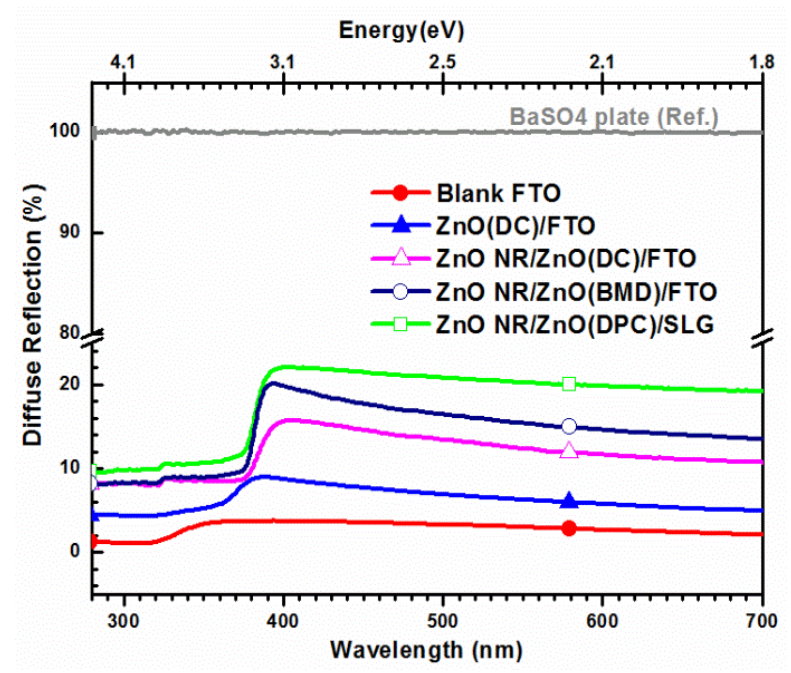

Figure 3. Diffuse reflection spectra of nanostructured $\mathrm{ZnO}$ thin films grown on SLG and FTO substrates. Diffuse Reflection data of blank FTO substrate is also included in the graph for comparison purposes.

Figure 3 compares the diffuse reflection data of $\mathrm{ZnO}(\mathrm{DC})$ thin film (solid triangle), $\mathrm{ZnO} \mathrm{NRs}$ grown on $\mathrm{ZnO}(\mathrm{DC})$ seed layer (open triangle), $\mathrm{ZnO} \mathrm{NRs}$ grown on $\mathrm{ZnO}$ (DPC) seed layer (open rectangle), $\mathrm{ZnO}$ NRs grown on $\mathrm{ZnO}(\mathrm{BMD}$ ) seed layer (open circle), and blank FTO substrate (solid circle). The optical band gap $\left(\mathrm{E}_{\mathrm{g}}\right)$ of these samples were estimated from the Tauc plot generated by using diffuse reflection data together with the so-called Kubelka-Munk function $\left(\mathrm{F}\left(\mathrm{R}_{\infty}\right)\right)[2]$ and displayed in figure 4 below.

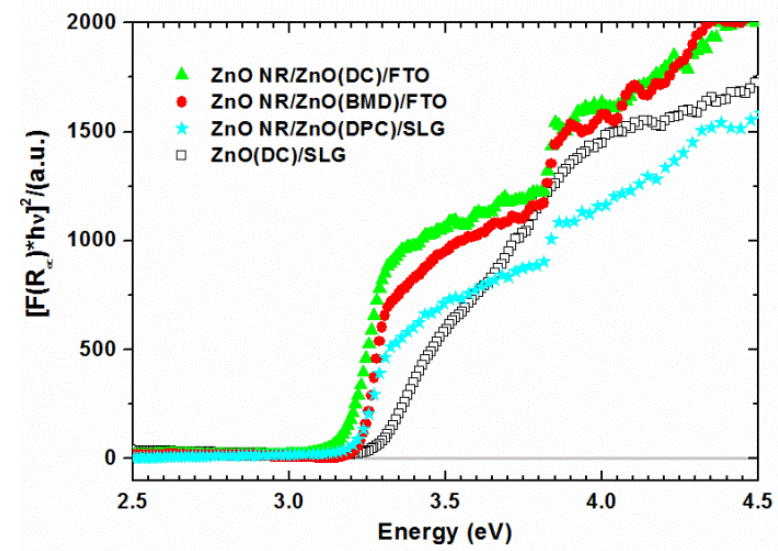

Figure 4. Tauc plot for estimating band gap of $\mathrm{ZnO}(\mathrm{DC}) / \mathrm{SLG}$ (open rectangle), $\mathrm{ZnO} \mathrm{NR} / \mathrm{ZnO}(\mathrm{DPC}) / \mathrm{SLG}$ (solid star), $\mathrm{ZnO} \mathrm{NR} / \mathrm{ZnO}(\mathrm{BMD}) / \mathrm{FTO}$ (solid circle) and $\mathrm{ZnO} \mathrm{NR} / \mathrm{ZnO}(\mathrm{DC}) / \mathrm{FTO}$ (solid triangle) thin films using diffuse reflection data.

As can be seen from figure 4, the optical band gap for $\mathrm{ZnO}(\mathrm{DC}) / \mathrm{SLG}, \mathrm{ZnO}$ $\mathrm{NR} / \mathrm{ZnO}(\mathrm{DPC}) / \mathrm{SLG}, \mathrm{ZnO} \mathrm{NR} / \mathrm{ZnO}(\mathrm{BMD}) / \mathrm{FTO}$, and $\mathrm{ZnO} \mathrm{NR} / \mathrm{ZnO}(\mathrm{DC}) / \mathrm{FTO}$ were estimated to be $\sim 3.30, \sim 3.20, \sim 3.25$ and $\sim 3.18 \mathrm{eV}$ respectively and they are in good agreement with the reported band gap of nanostructured $\mathrm{ZnO}$ thin films ([2] and refs. 
therein). To supplement optical band gap measurements of nanostructured $\mathrm{ZnO}$ film as well as to identify defect-related emission, PL measurements were also carried out at room temperature and depicted in figure 5. Form the literature, most PL spectra of $\mathrm{ZnO}$ thin film [10-12] and ZnO NRs [8, 13-15] show both the $380 \mathrm{~nm}$ UV emission feature and a much broader emission feature in the visible region $(500-600 \mathrm{~nm})$ [13]. The luminescent peak centering at $380 \mathrm{~nm}$ has been attributed to the near-band-edge (NBE) transition of $\mathrm{ZnO}$ due to the recombination of free excitons, while the luminescent features in the visible region have been attributed to the various defects, such as oxygen vacancies $\left(\mathrm{V}_{\mathrm{o}}\right)$, oxygen interstitials $\left(\mathrm{O}_{\mathrm{i}}\right)$ and zinc interstitials $\left(\mathrm{Zn}_{\mathrm{i}}\right)$ etc., present in the $\mathrm{ZnO}$ crystal lattice $[13,14]$. Therefore, the quality of synthesized $\mathrm{ZnO}$ can be assessed simply by estimating the ratio of the UV and Visible luminescent peak intensities $\left(\mathrm{I}_{\mathrm{uv}} / \mathrm{I}_{\mathrm{vis}}\right)$ [15].

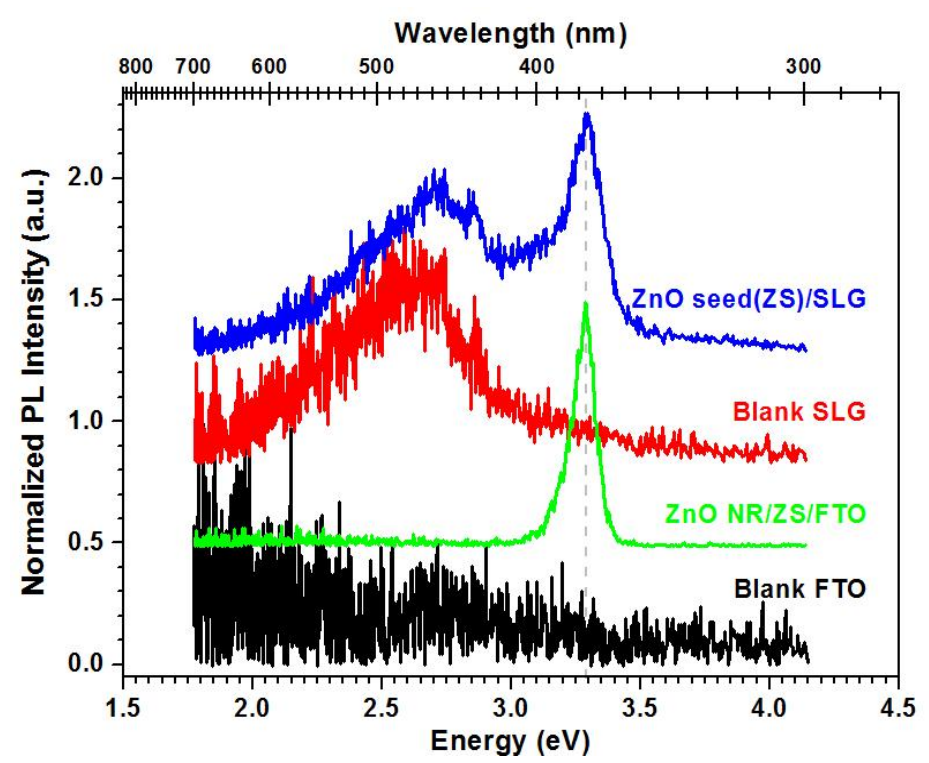

Figure 5. Normalized PL spectra (vertically offset for clarity) of ZS , ZnO NRs films, blank SLG, and blank FTO substrate recorded at room temperature. The PL intensity is normalized with respect to the highest peak height for all samples. The broad peak at $\sim 2.6 \mathrm{eV}(\sim 490 \mathrm{~nm})$ in panel originates from underlying SLG substrate.

In figure 5, the PL spectra of blank SLG (red curve) and FTO substrate (black curve) are compared and contrasted with that of $\mathrm{ZnO}(\mathrm{DC}) / \mathrm{SLG}$ (blue curve) and $\mathrm{ZnO}$ $\mathrm{NR} / \mathrm{ZnO}(\mathrm{DC}) / \mathrm{FTO}$ (green curve) thin films. Notice the PL spectrum of blank FTO substrate is featureless. In the case of $\mathrm{ZnO}(\mathrm{DC}) / \mathrm{SLG}$ (blue curve) sample, the broad band feature centering at $\sim 2.6 \mathrm{eV}(\sim 490 \mathrm{~nm})$ in the PL spectra may originate from the underlying SLG substrate, as this feature is absent in the relatively thicker and dense $\mathrm{ZnO} \mathrm{NR/} \mathrm{ZnO}(\mathrm{DC}) / \mathrm{FTO}$ (green curve) films (see also figure 2(e) and 2(e)). Strikingly, both $\mathrm{ZnO}$ (DC)/SLG and $\mathrm{ZnO} \mathrm{NR} / \mathrm{ZnO}(\mathrm{DC}) / \mathrm{FTO}$ sample displayed a sharp near-bandedge (NBE) at $\sim 378 \mathrm{~nm}(\sim 3.25 \mathrm{eV})$ and barely detectable green-yellow emission peak(s) in the RT-PL spectra. This PL feature is indicating high crystalline quality of our drop casting synthesized $\mathrm{ZnO}$ seed and hydrothermally grown $\mathrm{ZnO} \mathrm{NRs}$ on $\mathrm{ZnO}$ (DC) seed [2, $15]$ presumably with no or very low defect densities. In addition, the NBE value $(\sim 3.25$ $\mathrm{eV})$ from PL spectra is reasonably in good agreement with the estimated optical band gap $(\sim 3.18-3.25 \mathrm{eV})$ of the $\mathrm{ZnO} \mathrm{NRs}$ using diffuse reflection data. It is worth noting that 
both $\mathrm{ZnO}(\mathrm{DC})$ and $\mathrm{ZnO} \mathrm{NR}$ grown by facile chemical routes produced defect free good crystalline and optical quality materials, which is desirable for $\mathrm{ZnO} / \mathrm{Cu}_{2} \mathrm{O}$ based device applications [3]. Further experimental investigations are currently in progress to confirm the presence of green-yellow defects in hydrothermally grown ZnO NRs atop the BMD seed layer and the DPC seed layer with and without post-heat treatment in different ambient conditions.

\section{CONCLUSIONS}

In summary, $\mathrm{ZnO}$ seed layer have been successfully deposited by three different techniques and among them drop casted $\mathrm{ZnO}$ seed layers exhibit the highest $c$ axis texturing evident from the XRD analyses. XRD analyses also evidenced that $\mathrm{ZnO}$ NRs hydrothermally grown on $\mathrm{ZnO}(\mathrm{DC})$ seed exhibit higher $c$-axis texturing compared to those grown on other seed layers. The SEM micrographs reveal that pre-depositing a $\mathrm{ZnO}$ seed layer is beneficial for growing aligned $\mathrm{ZnO} \mathrm{NRs}$ along the $c$-axis direction parallel to the substrate normal. The optical band gap of nanocrystalline $\mathrm{ZnO}$ seed and $\mathrm{ZnO}$ NRs estimated by the UV-VIS-NIR spectroscopy were found to be $3.30 \mathrm{eV}$ and in the range $3.18-3.25 \mathrm{eV}$ respectively and consistent with the reported results in the literature. The RT-PL analyses further confirmed that $\mathrm{ZnO}$ NRs grown on $\mathrm{ZnO}$ (DC) seeded substrate are single crystalline like and free from defect-related green-yellow emission peaks. Among the three different seeding techniques for generating $c$-axis oriented $\mathrm{ZnO} \mathrm{NRs}$, drop casted seeding technique yielded the best nanorods with highest crystallite size $(L C \sim 45 \mathrm{~nm})$, texturing (TC 3.46), and a defect-free sharp optical bandgap which could be useful for various device applications.

\section{ACKNOWLEDGMENTS}

S.F.U. Farhad is indebted to Mr. Muklesur Rahman for providing a dip-coated thin seed layer sample during this study.

\section{REFERENCES}

[1] M. N. R. Ashfold, R. P. Doherty, N. G. Ndifor-Angwafor, D. J. Riley, and Y. Sun, Thin Solid Films, 515, 8679 (2007).

[2] S. F. U. Farhad, N. I. Tanvir, M. S. Bashar, M. S. Hossain, M. Sultana, and N. Khatun, Bangladesh J. Sci. Ind. Res., 53(4), 233 - 244 (2018).

[3] S. F. U. Farhad, PhD. Thesis, University of Bristol, 2016.

[4] M. R. Islam, J. Podder, S. F. U. Farhad, and D. K. Saha, Sensors \& Transducers Journal, 134, 170 (2011).

[5] S. F. U. Farhad, R. F. Webster, and D. Cherns, Materialia, 3, 230 (2018).

[6] D. Bao, H. Gu, and A. Ku, Thin Solid Films, 312, 37 (1998).

[7] J. S. Kim, H. A. Marzouk, P. J. Reucroft, and J. C. E. Hamrin, Thin Solid Films, 217, 133 (1992).

[8] Y. Yin, Y. Sun, M. Yu, X. Liu, B. Yang, D. Liu, S. Liu, W. Cao, and M. N. R. Ashfold, RSC Adv., 4 (84), 44452-44456 (2014).

[9] M. Mekhnache, A. Drici, L. Saad Hamideche, H. Benzarouk, A. Amara, L. Cattin, J. C. Bernède and M. Guerioune, Superlattices and Microstructures, 49 (5), 510-518 (2011).

[10] M. Çopuroğlu, L. H. K. Koh, S. O’Brien, and G. M. Crean, Journal of Sol-Gel Science and Technology, 52 (3), 432-438 (2009).

[11] Y. Chen, D.M. Bagnall, Z. Zhu, T. Sekiuchi, Ki-tae Park, K. Hiraga, T. Yao, S. Koyama, M.Y. Shen and T. Goto, Journal of Crystal Growth, 181, 165 (1997).

[12] Y.-S. Kim, W.-P. Tai, and S.-J. Shu, Thin Solid Films, 491, 153 ( 2005).

[13] A. B. Djurišić, Y. H. Leung, K. H. Tam, Y. F. Hsu, L. Ding, W. K. Ge, Y. C. Zhong, K. S. Wong, W. K. Chan, H. L. Tam, K. W. Cheah, W. M. Kwok and D. L. Phillips, Nanotechnology, 18, 095702 (2007).

[14] Y. Sun and M. N. R. Ashfold, Nanotechnology, 18, 245701 (2007).

[15] Y. Sun, G. M. Fuge, and M. N. R. Ashfold, Superlattices and Microstructures, 39, 33 (2006). 